\title{
RESISTÊNCIA E JORNALISMO NA LITERATURA DE ANTONIO CALLADO
}

\section{RESISTANCE AND JOURNALISM IN ANTONIO CALLADO'S LITERATURE}

\author{
Marco Aurelio Reis \\ Doutor em Ciência da Literatura pela Universidade Federal do Rio de Janeiro \\ Graduado em Jornalismo pela Escola de Comunicação da Universidade Federal do Rio de Janeiro \\ Bolsista do Programa de Pesquisa e Desenvolvimento Universidade Estácio de Sá do Rio de Janeiro \\ Professor bolsista da Universidade Aberta do Brasil/Universidade Federal de Juiz de Fora \\ Professor da Universidade Estácio de Sá \\ E-mail: mreis1968@gmail.com
}

\section{RESUMO}

Após meio século do golpe militar no Brasil, obra do jornalista e escritor Antonio Callado surge como importante elemento de reconstrução do período de censura a jornais. Três romances do autor (Quarup, Bar Don Juan e Reflexos do Baile), escritos após1964, aparecem como elementos reflexivos sobre resistência armada ao golpe e também como obras de militância intelectual em prol da democracia. A proposta é reabrir o debate em torno dos três romances, convidando para uma releitura crítica deles nesse novo momento histórico em que a memória da ditadura tem o relevante papel de impedir a repetição daqueles tristes episódios.

Palavras-chave: Callado, Ditadura Militar, Resistência

\begin{abstract}
After half a century of military coup in Brazil, journalist and writer Antonio Callado work emerges as an important reconstruction element of the period of censorship of newspapers. Three novels of the author (Quarup, Bar Don Juan and Ball Reflexes), written after 1964 appear as reflective elements on armed resistance to the coup and as works of intellectual activism for democracy. The proposal is to reopen the debate on the three novels, calling for a critical re-reading in this new historical moment in which the memory of the dictatorship has the role to prevent the repetition of those sad episodes.
\end{abstract}

Keywords: Callado, Military Dictatorship, Resistance 


\section{INTRODUÇÃO}

Os 50 anos do Golpe Militar de 1964, revistados no biênio 2014/2015 pelas Comissões da Verdade formadas em todo o País, serviram para um movimento inédito de reflexão que fomentou o debate em torno da produção intelectual de resistência ao regime instaurando entre abril daquele ano e junho de 1985 e também sobre os excessos cometidos pelos agentes daquela ditadura. Essa bem-vinda efervescência intelectual serviu de convite para releituras de obras e autores. Nesse contexto, a proposta do presente trabalho é reabrir a discussão em torno do caráter alegórico dos romances Quarup, Bar Don Juan e Reflexos do Baile, do jornalista, escritor e dramaturgo Antonio Callado (1917-1997), os três escritos no calor da repressão política do período desencadeado após o Golpe Militar de 1964.

A fortuna crítica em torno da obra de Callado aponta, sobretudo em Quarup, um traço inerente ao neo-realismo produzido no Brasil no fim da década de 60 e ao longo da década de 70 : a construção de um romance alegórico em meio à tentativa de representar a realidade histórica concreta (ARRIGUCCI,1979). Ou seja, a construção de uma narrativa a partir de um fato ou personagem específico com o objetivo de retratar uma situação geral. Essa técnica diretamente relacionada à prática em jornais diários pode ser notada quando uma reportagem sobre um acidente natural é aberta pelo drama da família que perdeu a casa e um dos filhos.

Seria essa a principal chave de entrada para leitura das obras citadas? A proposta do presente trabalho é, com base nas considerações de Schwarz (1999), traçar pistas de leitura para além dessa preponderante consideração de que Callado, dentro da tradição geral do romance brasileiro, produziu uma complexa, mas "malograda", tentativa de representar o que foi a realidade por ter priorizado o uso da alegoria na construção de sua narrativa. Nessa revisita à obra do jornalista, o convite é desvelar nela uma trincheira intelectual contra a censura à imprensa imposta pelo regime militar.

\section{LITERATURA PARTICIPANTE DO JORNALISTA ANTONIO CALLADO}

Como sublinha Cândido (1987), a literatura do período histórico que sucedeu ao golpe de 1964 pode ser classificada como participante, tendo sido consolidada na primeira década do Regime Militar $^{(1)}$. Antonio Callado é um de seus expoentes, podendo ser classificado, por sua origem jornalística, como “cronista do golpe". Como dito anteriormente, Quarup, Bar Don Juan e Reflexos do Baile são as três obras do autor diretamente ligadas ao processo histórico dos primeiros anos da ditadura militar, marcados pelo autoritarismo dos governos comandados por generais; pela prisão, tortura e morte dos opositores ao novo status quo. 
Quarup (1967) é o terceiro romance de Callado. Os dois primeiros, Assunção de Salviano (1954) e Madona de Cedro (1957), abordam a questão política, mas o tema central é a religiosidade. Os dois posteriores, Bar Don Juan (1971) e Reflexos do Baile (1976), a exemplo de Quarup, tratam mais abertamente do período de "amargura política" (CANDIDO, 1987) que se sucedeu à instauração do Regime Militar, sendo ambientados no calor dos movimentos de resistência ao novo regime.

A ficção de Callado neste período é marcada claramente por sua trajetória pessoal. Com a experiência de quem integrou o movimento guerrilheiro ligado a Leonel Brizola 2, tendo sido preso seis vezes pela ditadura, o escritor não escondeu a relevância do guerrilheiro Che Guevara e do pensamento de esquerda em seus textos do período.

Sua trajetória pessoal como jornalista também é outra influência marcante em seus textos do período pós-1964, uma vez que a censura aos jornais (ampliada após 1968, com o Ato Institucional Número 5, AI-5) impediria que muitos temas tratados nos três romances citados pudessem figurar nas reportagens da imprensa diária e semanal.

Quarup é a mais conhecida das três obras, seja pela surpresa que despertou ao ser publicada, seja por sua transposição para o cinema em 1989. O romance é protagonizado pelo personagem padre Nando, cujos conflitos interiores (celibato, atuação política e vida religiosa) vão servir de fio condutor para relatos quase jornalísticos das inquietações do momento, entre elas a resistência armada ao governo militar.

Além disso, Quarup tem evidente intenção de chocar, trazendo à tona conflitos em profusão e nem sempre fiéis à verossimilhança declarada de sua proposta, como quando personagem sertanista morre após saber que sua proposta de proteção aos índios poderia dizimar tribos e quando Nando salta do conflito com o limite celibatário para cenas de orgias sexuais e de inusitadas aulas de iniciação sexual.

Vivendo num mosteiro em Recife, Nando demonstra temer seu ideal de atuação política (criar com índios amazônicos sociedade semelhantes às reduções jesuíticas do século XVIII) diante do risco de trair o voto de castidade com índias. O conflito se resolve quando, ainda na capital pernambucana, é iniciado sexualmente por uma inglesa. Livre do obstáculo inicial pelo caminho mais inusitado, o padre se prepara para ir ao Xingu, passando antes pelo Rio de Janeiro, onde, a pretexto de entrar em contato com o Serviço de Proteção ao Índio (SPI), dá prosseguimento a suas experiências sexuais e ao mesmo tempo se inicia no consumo de drogas.

No romance, são duas as vezes que Nando vai ao Xingu. Na primeira, o fato relevante é a fuga de um dos personagens (a cobiçada Sônia) para viver com um índio. Na segunda, anos mais tarde, a busca é pelo centro geográfico do Brasil. Dessa vez a cobiçada é a também jovem Francisca, que tivera o noivo morto pela repressão política após voltar da Europa. Nando e 
Francisca se relacionam, fazem sexo na floresta, desencadeando no romance a dramática morte de uma tribo indígena (dizimada por doenças trazidas pelos brancos) e a morte sem propósito do sertanista Fontoura: bêbado, cai com o rosto sobre um formigueiro, bem no centro geográfico do Brasil.

Após a segunda expedição, Nando deixa a vida religiosa, volta a Recife com Francisca. Vão trabalhar como alfabetizadores de camponeses, quando ocorre o golpe de 1964. Nando resiste ao novo regime e é preso. Solto, percebe que fora abandonado por Francisca (que voltou para a Europa) e mergulha no sexo livre com inúmeras mulheres e troca o ofício de alfabetizador pelo ensino de sua técnica sexual. Por fim, parte para o sertão onde se junta a um movimento guerrilheiro de oposição ao regime.

$\mathrm{Na}$ incursão na ambiência do sexo livre, cabe destacar um traço da realidade urbana do período e da nítida intenção de chocar, marcas do brutalismo apontado por Bosi (1975) como uma das características da literatura que se formaria ao longo dos anos de chumbo.

Dormia noites a fio nas pensões de mulheres, a da Pórcia ou da Arlete, conversando com Marta Branca e Marta Preta, com Sancha e Severina, que eram todas amigas suas, ou voltava a dormir com Cecília que tinha conhecido brevemente em outros tempos. Quando chegava alguma nova, exasperada e seca, Nando lhe dava dinheiro sem nada pedir em troca, com quem apazigua índio brabo. Era o meio de começar a mostrar carinho e amor às que tinham sido levadas a se calcularem em moedas. Às vezes, desconfiadas, vendo Nando cercado das outras, elas exigiam que ele aceitasse a mercadoria.

- Por que é que tu não vem comigo? Tem nojo?

Nando se deitava ao lado dessas gatas bravas e de tal forma e com tanta ternura se fazia ele o profissional que elas se tornavam a freguesa tímida e assustada .... (CALLADO, 1967, p. 383).

Já na conversão de Nando da crise de identidade para a guerrilha, o traço evidente da narrativa engajada, iniciada logo após o golpe militar e que iria se repetir em seus romances seguintes.

Reflexos do baile (1976), obra preferida do autor 3, tem a nítida intenção de traduzir o caótico momento, de indefinição, conflito e desesperança. Tendo a narrativa centrada no sequestro de um embaixador durante um baile, personagens guerrilheiros, diplomatas, policiais e familiares desses personagens confundem-se e só se desvelam aos poucos, por intermédio de falas intercaladas, bilhetes e cartas, criando um mosaico de tão modo emaranhado que só no fim da obra é possível se traçar seu enredo.

Em sua construção, marcada pelo distanciamento estético que aproxima o leitor, um narrador-organizador monta uma obra de resistência ao processo político repressivo e à modernização autoritária aos moldes do estilo caracterizado por Franco (1998), ponto o leitor diante do que o autor quer retratar. Esse narrador surge em meio aos textos fragmentários, no formato de pequenos relatos explicativos. 
Custo a dormir, de alcoolizado que estou, suponho, e de revirar na cabeça a lembrança estapafúrdia de algo que me escapou enquanto compunha minha entry: por que devo guardar para mim, conforme me pediram ambos, que Taher Collins, além de padre, é engenheiro eletricista? Hom'essa! Tomarei um Engov com um Remy Martin e bastante soda (CALLADO, 1976, p. 103).

A experimentação formal proposital evidencia uma atmosfera imprecisa, porque estilhaçada e pantanosa, mas ao mesmo tempo, confunde, aproxima e instiga o leitor. O mosaico reproduz o difícil trabalho jornalístico do período, em que a censura e a autocensura impediam o esclarecimento de acontecimentos.

Bar Don Juan, diferente de Quarup, tem toda a trama centrada na resistência ao regime militar. Também diferente de Reflexos do Baile, tem a narrativa linear, clara, nada experimental. Nele, a atmosfera do momento histórico, diretamente relacionada ao regime militar, aflora límpida e com ares verossímeis. O bar que dá título à obra foi inspirado em um bar do Rio de Janeiro frequentado por intelectuais, o Antonius.

Visto pela crítica corrente como retrato da chamada "esquerda festiva" (LEITE, 1988), a obra dá notícia do despreparo da esquerda intelectual para enfrentar a ditadura militar. Fala das contradições dessa esquerda. Falta povo (outra constante crítica aos romances de Callado), mas o pouco que há é o suficiente para igualar torturador e guerrilheiro em humanidade. Dá notícia sobre a execução de Che Guevara, um registro nobre se for levada em conta a censura que cercou essa informação nos jornais brasileiros. Fala, mesmo sem expressa intenção do autor, do projeto de desenvolvimento econômico dos governos militares.

Bar Don Juan é editado dois anos depois do AI-5, no calor do recrudescimento da censura, da guerrilha armada e da repressão violenta aos movimentos contra a Ditadura Militar. A narrativa linear evidencia a intenção jornalística do autor de perpetuar uma atmosfera que predominou no pós-1968, sem medo de desagradar seus pares de esquerda ou levantar ira de censores. Em entrevista à revista IstoÉ de 26 de setembro de 2001, Fernando Gabeira, ex-guerrilheiro e um dos que do exílio criticaram negativamente a obra no seu lançamento, elogia essa intenção: "Foi ótimo que o livro não tenha sido feito como gostaríamos. Ele não sobreviveria até hoje". Gabeira disse ainda que do texto ficou a "maneira como ele mostra a realidade na visão estética de Callado. É isso que permanece nas grandes obras"4.

Bar Don Juan narra a fracassada tentativa de um grupo de intelectuais de esquerda do Rio de Janeiro de reforçar em armas e braços a guerrilha revolucionária comandada por Che Guevara na Bolívia. Esses intelectuais contam com o apoio arregimentado de um garçom e de um ex-sargento do Exército brasileiro. Os personagens passam a maior parte da trama se preparando para unir forças ao guerrilheiro argentino que, em solo boliviano, daria partida a uma revolução 
nos países da América do Sul. Esses intelectuais, porém, não abandonam seus hábitos de classe média carioca. Fazem discussões ideológicas na mesa de um bar, o Bar Don Juan, onde tomam uísque e se deslocam de avião comercial.

Simultaneamente à captura e morte de Che, também contadas na trama, três dos principais personagens são mortos antes mesmo de deixar o Brasil, no momento em que já estavam em Corumbá, no Mato Grosso. Um enquanto tentava expropriar (eufemismo de esquerda para assalto) um banco. Outros dois a tiros delatados acidentalmente por um comparsa atrapalhado enquanto atravessam a barco armas para a Bolívia. Desse ponto ao fim a narrativa se concentra em torno de uma personagem, antes cética em relação à resistência armada à ditadura, que ruma para clandestinidade e mergulha na guerrilha. Essa personagem é Laura, mulher do escritor João, casal que funciona como fio condutor de toda a trama.

Olhando para os aspectos levantados por Roberto Schwarz no ensaio "Pai de Família" (1992), cabe chamar a atenção para a orelha do livro, publicada na segunda edição, de 1972. Nela, há a nítida intenção de não polemizar. Ditadura e guerrilha são traduzidas pelo neutro termo "acontecimentos". Toda a luta armada, com o recrudescimento dos ditadores, é resumida diplomaticamente pela expressão "confusa e inquietante período". A orelha levanta, ainda, um álibi para o autor, lembrando que ele e outros escritores do período, como Carlos Heitor Cony e Joel Silveira, se preocupam, antes, com as repercussões existenciais", e não com a então censurável "análise sociológica e política".

Bar Don Juan é editado pela primeira vez em 1971, portanto como já foi dito após o AI-5, o golpe dentro do golpe como definiu Schwarz (1992). O editor da Enio Silveira, dono da Editora Civilização Brasileira, que ousou publicar Bar Don Juan no calor da repressão política, usou de uma artimanha para lançar o livro. Não fez divulgação ampla, confiou no burburinho que a obra ia causar na esquerda e a distribuiu pelo país e colheu os frutos do esgotamento da primeira edição em menos de um ano. Ao retratar a esquerda festiva, atrapalhada e fracassada, Callado não agradou seus pares. Mesmo assim foram seis edições esgotadas. A jornalista Ana Arruda Callado, viúva do escritor morto aos 80 anos em 1997, reeditou Bar Don Juan em 2001. Naquele ano, o deputado federal Fernando Gabeira concedeu a entrevista, já citada neste trabalho, à revista IstoÉ.

\section{REALISMO E ALEGORIA}

Cabe ainda olhar para o livro Bar Don Juan buscando o chamado impulso realista, apontado pelos dois críticos como uma das marcas da literatura engajada na qual comumente se insere a obra de Callado no período logo posterior a 64. O impulso realista mais marcante da obra 
são as citações sobre a atuação do Partido Comunista no período histórico, na contradição entre discurso e prática e aparelhamento burocráticos que seriam citados abertamente posteriormente por Schwarz (1978). Em Bar Don Juan salta aos olhos quando o personagem João conversa com emissário de Che Guevara na já citada viagem a São Paulo. Diz o emissário:

Quando a gente se conforma em ser a gente mesmo a gente dorme. Mas será que Mário Monje consegue dormir alguma noite da sua vida?

João olhou Eustáquio (emissário de Che), meio espantado com o nome desconhecido atirado à conversa.

- Monje é o homem do PC na Bolívia _disse Eustáquio _ Só ajudava a gente se fosse ele próprio o chefe da guerrilha.

- O Partido ficou neutro? _ disse João.

- Tomara que fique só neutro. Foi logo que a gente chegou a Nancahuazu que ele veio ver o Comandante. E o que é que ele tinha a propor? Que o Comandante não fosse o Comandante. O Comandante seria Mário Monje. Como sabiam que o comandante não ia aceitar uma coisa dessas devem ter inventado a proposta para conseguir o que queiram: não ter nada que ver com a guerilha (CALLADO, 1972, p.76).

Na página 108, o pensamento do PC é resumido. Em conversa com companheiro guerrilheiro um terceiro personagem explica, em novo impulso realista, que o Partidão, como é chamado o Partido Comunista Brasileiro, pensa que a revolução só poderia ser feita num país de cada vez. "Feito cagar", diz o interlocutor. "Mais ou menos, mal comparando", responde o personagem, para emendar uma lição de ideologia comunista:

Daí, só tem cinqüenta anos que a gente espia a URSS (antiga União Soviética) fazendo cocô sozinha e ela ainda não acabou. A gente precisa esperar que ela acabe.

- Mas onde entra o trotskismo nessa cagada?

- O Trotski achava que todo o mundo devia cagar ao mesmo tempo, numa caganeira universal, até sair o último verme capitalista dos intestinos dos países pobres. Fedia tudo ao mesmo tempo e depois fazia-se a faxina (CALLADO, 1972, p.108).

Cabe ainda sublinhar a ousadia desse impulso, uma vez que a obra, como já foi dito, foi publicada no calor do AI-5. Outro impulso realista, bem jornalístico, mas sem a pretensão da objetividade, está no trecho em que a modernização proposta pela ditadura é mencionada na obra. Tal modernização seria destacada posteriormente por Schwarz e, em Bar Don Juan, parece surgir mesmo sem ser intenção explícita do autor. No trecho, da página 201, um engenheiro aparece falando de uma proposta de logística de transporte por rio. Cabe lembrar que os problemas com transporte foram um dos entraves do programa de desenvolvimento econômico dos militares, batizado de Milagre Brasileiro. Diz o engenheiro: 
Vamos fazer a interligação das Bacias do Amazonas e do Prata. Não existe nenhuma razão válida para não se ir de Belém do Pará a Buenos Aires esticado numa espreguiçadeira no convés de um navio. O Brasil inteiro é uma região como esta aqui (Mato Grosso), de Águas Emendadas (CALLADO, 1972, p.201).

O reducionismo do procedimento alegórico vem em torno do mesmo engenheiro. De tão real ao retratar o projeto de modernização do governo ditatorial militar, ele passa a alegórico quando uma personagem grávida vê uma personagem sequestrar o avião em que retornavam presos do Mato Grosso para o Rio de Janeiro.

Foi Da Glória quem primeiro entendeu o que acontecia e cravou as unhas no braço de Mariana. Um segundo depois do avião inteiro subia um murmúrio de assombro e de meio pânico. Mariana sentiu o coração feito um pássaro aterrado dentro do peito, cerco instintivamente com os braços o ventre habitado, só vendo ao redor nas caras assustadas o reflexo do seu medo, até que viu a de Luciano (o engenheiro), a cara de Luciano, pálida mas que se iluminava num sorriso (CALLADO, 1972, p.208).

Se o sorriso durante o sequestro do avião do engenheiro entusiasmado com o projeto de modernização proposto pelos militares parece inusitado, mais ainda é a certeza de Mariana, de dentro do avião, de que ele seguia rumo ao Norte, a "direção da ilha de Cuba".

\section{CONSIDERAÇÕES FINAIS}

Cabe ver Guarup, Bar Don Juan e Reflexos do Baile como reflexos de um olhar maduro. Callado tinha 55 anos quando escreveu os romances. Tinha feito a cobertura jornalística dos horrores da Segunda Guerra Mundial, a partir da Inglaterra e da França, como correspondente. Já tinha o mérito de ser o único brasileiro a cobrir a guerra da Coreia a partir da vermelha Coreia do Norte. Tinha sido preso seis vezes pela ditadura militar, tendo os direitos políticos cassados e convivido com os censores na redação do Jornal do Brasil.

Em uma análise além da preponderância alegórica observada na própria caracterização dos personagens guerrilheiros da esquerda festiva brasileira, pode-se perceber em Bar Don Juan o exorcismo do fantasma do relato proibido a cerca da morte de Che Guevara, em 1967. Na obra Che aparece messiânico, como quando pede a um companheiro de guerrilha que diga a gerações futuras para compreenderem aquele tempo em que médicos "desceram dos lazarentos para matar homens sãos" (CALLADO, 1972, p. 163). Na execução de Che, mais messianismo: oficiais bolivianos são retratados como sendo obrigados a apontar a arma para forçar o sargento Terán a disparar o tiro mortal contra o coração do guerrilheiro. 
Disse o Comandante que como em sua vida não acumulava nenhuma riqueza e como os países leprosos eram muitos deixava de herança pedaços de si mesmo a serem semeados por todas as terras em que vivera. Que mandassem à Argentina sua mão direita e ao Brasil sua mão esquerda pois ambas continuariam fazendo a única coisa que tinha aprendido a fazer a fundo, a saber, a revolução. De suas mãos não necessitavam os cubanos que já fizeram a revolução, em lugar de usar seu santo nome em vão, mas mandava aos cubanos seu coração para que não perdessem a ternura. E o Comandante ficou em silêncio, esperando que o fuzilamento libertasse de seu corpo a liça, feito uma alma. [...] Quando o viram morto os oficiais arrastaram o corpo do Comandante e colocaram seus pulsos sobre uma mesa. Depois ergueram juntos uma machadinha de açougue e deceparam primeiro a mão esquerda e depois a mão direita do Comandante (CALLADO, 1972, p.164 e 165).

Quarup, Bar Don Juan e Reflexos do Baile revelam ainda uma sociedade bem interessante. A guerrilha formada por intelectuais tendo integrantes do povo como empregados subalternos, arrolados pelos acontecimentos. Guerrilheiros que tomam uísque falsificado e subornam policiais para escapar de um mero flagrante de briga em bar. Um torturador pai de família que anda de ônibus e a pé enquanto os guerrilheiros intelectuais só se movimentam de carro.

Os três romances trazem ainda algo sutil que se comunica aos dias de hoje, mesmo sem ter sido mencionado pelo autor nas entrevistas concedidas por ele: uma espécie de brasilidade em que o pensamento e comportamento arcaicos, típicos da elite nacional, sobrevivem mesmo no moderno discurso da esquerda. Uma falha que mina as intenções de guerrilha e denuncia o despreparo da resistência armada ao regime num momento em que o discurso preponderante entre os intelectuais era de esperança, com a adesão de estudantes universitários ao pensamento de esquerda.

Nessa sutileza os três livros com ares de ficção, como forma de revelação e conhecimento do País, parecem completos mesmo que esse país seja revelado não pela totalidade e, sim, pela alegoria.

\section{NOTAS}

1 Segundo Skidmore (1976), o chamado Regime Militar foi decorrente do "trauma político" que, em 31 de março de 1964, depôs do governo o presidente João Goulart, vice-presidente eleito em 1961 conduzido ao Planalto após a renúncia, no mesmo ano do pleito, de Jânio Quadros, que se elegera presidente. Goulart teve dificuldades de assumir o posto vago pela renúncia por sua ligação com o populismo getulista e sua identificação com temas associados ao comunismo histórico, como seu projeto de Reforma Agrária. A posse ocorreria só em 1963, após plebiscito nacional. Com sua deposição, instaurou-se uma ditadura militar, com limitada participação dos movimentos civis que a apoiaram sua instalação. Essa ditadura se estendeu até 1985, quando de forma indireta se elegeu o primeiro presidente civil (Tancredo Neves).

2 CALlado, A Entrevistas com Antônio Callado. In: O Nacional e o Popular na Cultura Brasileira: Artes Plásticas e Literatura. 2 ed. São Paulo: Brasiliense, 1982, p. 236.

3 SUZUKI, Matinas, STYCER, Maurício. Antonio Callado chega aos 80 e revê obra, Folha de S. Paulo, 26/01/97, na qual o escritor, autor de 'Quarup', afirma que sua única obra importante é o romance 'Reflexos do Baile', de 76

4 26/9/2001, página 22, seção A Semana / Livros

Linguagens - Revista de Letras, Artes e Comunicação ISSN 1981-9943 Blumenau, v. 10, n. 2, p. 406-415, mai./ago. 2016 


\section{REFERÊNCIAS}

ARRIGUCCI JR, Davi. O Baile das Trevas e das Águas. In: Achados e perdidos: ensaios de crítica. São Paulo: Polis, 1979.

BOSI, Alfredo (org). O conto brasileiro contemporâneo. São Paulo: Cultrix, 1975.

CALLADO, Antonio. Quarup.. 12. ed. Rio de Janeiro: Nova Fronteira, 1998.

, Antonio. Bar Don Juan. 2. ed. Rio de Janeiro: Civilização Brasileira, 1972.

, Antonio. Reflexos do Baile. $3^{\text {a }}$ ed. Rio de Janeiro: Paz e Terra, 1977.

CANDIDO, Antonio. A educação pela noite e outros ensaios. São Paulo: Atica, 1987.

O discurso e a cidade. São Paulo: Duas Cidades, 1993.

CRUZ, Cláudia Helena da. Bar Don Juan (1971). De Antonio Callado: Impasses Políticos e Estéticos do Romance Engajado, Revista Fênix de História e Estudos Culturais, Novo Hamburgo, 2005. Disponível em http://www.revistafenix.pro.br/pdf2/Artigo $\% 20$ Claudia $\% 20$ Helena\%20Cruz.pdf, acessado em 4 de abril de 2015.

FRANCO, Renato. O Romance de Resistência dos Anos 70. Chicago, XXI Lase Congress, 1998. Disponível em http://bibliotecavirtual.clacso.org.ar/ar/libros/lasa98/Franco.pdf. Acessado em 02 de abril de 2015.

HOLLANDA, Heloísa Buarque de \& GONÇALVES, Marcos A. (1980). Política e literatura: a ficção da realidade brasileira. In: NOVAES, Adauto (Org.). Literatura - anos 70. Rio de Janeiro.

LEITE, Lígia Chiappini Moraes (org.). Antonio Callado. 2. ed. São Paulo: Nova Cultural, 1988. (Literatura Comentada).

REIS, Marco Aurélio. Bar Don Juan uma Proposta de Leitura. Revista Projetos Experimentais.com, Rio de Janeiro, 2007. Disponível em http://www.projetosexperimentais. com/Artigos/Callado.pdf, acesso em janeiro de 2015.

SCHWARZ, Roberto. Pai de família e outros ensaios. 2a ed. Rio de Janeiro: Paz e Terra, 1992

Que horas são? ensaios. São Paulo: Companhia das Letras, 1997.

Sequências brasileiras. São Paulo, Companhia das Letras, 1999.

SILVERMAN, M. A Ficção em Prosa de Antonio Callado. In: Moderna Ficção Brasileira: ensaios. 2. ed. Rio de Janeiro: Civilização Brasileira, 1982, p. 22.

SKIDMORE, Thomas. Brasil, de Getúlio a Castelo. Rio de Janeiro: Paz e Terra, 1976

SUZUKI, Matinas, STYCER, Maurício. Antonio Callado chega aos 80 e revê obra, Folha de S. Paulo, São Paulo, 26/01/97. 